\title{
OS LIMITES DA LINGUAGEM E DO MÍSTICO: ASSIMILAÇÃO DO PENSAMENTO SHOPENHAUERIANO POR WITTGENSTEIN
}

\author{
THE LIMITS OF LANGUAGE AND THE MYSTICAL: WITTGENSTEIN'S \\ ASSIMILATION OF SCHOPENHAUER'S THOUGHT
}

\author{
GLEISY PICOLI ${ }^{1}$ \\ Instituto Federal de São Paulo (São Roque) - Brasil \\ gleisypicoli@yahoo.com.br
}

\begin{abstract}
RESUMO: O objetivo primordial deste artigo consiste em analisar a assimilação do pensamento schopenhaueriano por Wittgenstein, no que diz respeito à relação entre a linguagem e o místico. No decorrer do texto, pretendemos mostrar que Wittgenstein, com a sua tão conhecida posição de que sobre o místico não se fala, pode ter se inspirado na doutrina schopenhaueriana da linguagem, cujos limites linguísticos são alcançados na negação da vontade, momento em que se abre uma passagem ao místico. De nossa interpretação se seguirá como consequência principal que a problemática central do Tractatus entre o dizer e o mostrar, comumente considerada característica distinta da filosofia de Wittgenstein, já pode ser lida no sistema de seu predecessor.
\end{abstract}

PALAVRAS-CHAVE: Schopenhauer; Wittgenstein; linguagem; místico.

ABSTRACT: The primary objective of this paper is to analyze Wittgenstein's assimilation of Schopenhauerian thought with regard to the relationship between language and the mystical. Throughout the text, we intend to show that Wittgenstein, with his well-known position that one does not speak about the mystical, may have been inspired by the Schopenhauerian doctrine of language, whose linguistic limits are reached in the negation of will, when it opens a passage to the mystical. From our interpretation it will follow as the main consequence that the central problematic of the Tractatus between saying and showing, commonly considered a distinct feature of Wittgenstein's philosophy, can already be read in the system of its predecessor.

KEYWORDS: Schopenhauer. Wittgenstein. Language. Mystic.

\section{O CONFLITO ENTRE O DIZERE O MOSTRARNA DOUTRINA SCHOPENHAUERIANA}

Schopenhauer discorre especialmente sobre a linguagem na $\$ 8$ de sua obra capital, O Mundo como Vontade e Representação, quando nos apresenta uma teoria da linguagem, formulada de modo tão simples, que pode ser sintetizada nas seguintes palavras: a linguagem é um produto da razão. Segundo Schopenhauer, a linguagem é o meio pelo qual o ser humano comunica os seus pensamentos, que nada mais são do que juízos compostos de representações abstratas (ou conceitos), os quais, por sua vez, têm como base as representações intuitivas

1 Doutora em Filosofia pela Universidade Estadual de Campinas (Unicamp) e professora substituta do Instituto Federal de São Paulo, campus São Roque. 
(intuições empíricas). Mas, para que esses conceitos sejam formados, é necessária a colaboração da razão, por isso, são produtos exclusivos dos seres humanos. Ademais, na visão schopenhaueriana, todo conceito ou representação abstrata deve ter como fundamento último a experiência, ou seja, algo que existe ou já existiu - noutros termos, todo conceito deve basear-se numa intuição empírica. Caso contrário, não se trata de um conceito, mas sim de uma mera palavra, vazia de conteúdo, como é o caso dos supostos conceitos: "absoluto", "infinito", "suprassensível" (W I, \$53, p.315), que não se fundamentam em nenhum objeto empírico e, por isso, não podem ser considerados verdadeiramente "conceitos". Schopenhauer fala da indispensabilidade da base empírica para que um conceito seja, de fato, um conceito, e não uma mera palavra, do seguinte modo:

[...] embora, pois, os conceitos sejam desde o fundamento diferentes das representações intuitivas, ainda assim se encontram numa relação necessária com estas, sem as quais nada seriam; relação que, por conseguinte, constitui toda a sua essência e existência. (W I, \9, p.47).

Nos Suplementos, o autor acrescenta:

[...] um instrumento tão importante da inteligência, como é o CONCEITO, manifestamente não pode ser idêntico com a PALAVRA, este mero sonido, que como impressão sensorial se esvanece no presente, ou como fantasma auditivo desaparecerá com o passar do tempo. Todavia, o conceito é uma representação, cuja consciência distinta e conservação ligam-se à palavra: por isso os gregos designavam palavra, conceito, relação, pensamento com o nome da primeira: ó $\lambda$ ópos. Não obstante, o CONCEITO é por inteiro diferente tanto da PALAVRA, à qual está conectado, quanto das intuições, das quais originou-se. (W II, cap.6, p.75-76).

A teoria schopenhaueriana da linguagem, no fundo, é herdeira da teoria kantiana do conhecimento, pois o que a linguagem trabalha em comunhão com a razão são as nossas representações abstratas, as quais, por sua vez, têm como base as intuições empíricas - e esse raciocínio está diretamente associado ao nosso modo de conhecer as coisas, segundo as formas a priori da sensibilidade, tal qual foi defendido por Kant. A consequência desse pensamento na filosofia schopenhaueriana é a de que não somos sequer capazes de pensar o que seja a experiência suprassensível, nem tampouco de dizer algo sobre ela, já que só podemos formar conceitos a partir de dados empíricos, logo, a nossa linguagem só alcança a experiência sensível. ${ }^{2}$ O âmbito além da experiência corresponde exatamente àquilo que Schopenhauer entende por místico: "misticismo", afirma Schopenhauer, "no sentido amplo do termo, é toda orientação para o sentimento imediato daquilo que não é alcançado pela intuição nem pelo conceito, portanto,

\footnotetext{
${ }^{2}$ Para Kant, porém, podemos pensar nos objetos como coisas em si mesmas, embora não podemos nunca as conhecer. "Para conhecer um objeto", afirma Kant, "é necessário poder provar a sua possibilidade (seja pelo testemunho da experiência a partir de sua realidade, seja a priori pela razão). Mas posso pensar no que quiser, desde que o meu conceito seja um pensamento possível" (KANT, KrV, BXXVI-BXXVII e p.25).
} 
em geral, por conhecimento algum" (W II, cap.48, p.728). Em termos schopenhauerianos, podemos dizer que o domínio do místico constitui "o QUÊ o mundo é" e diz respeito à coisa em si, enquanto que este mundo, onde estamos, é o da aparência e refere-se ao mundo "COMO ele é".

Vemos, pois, que Schopenhauer, por um lado, defende que o âmbito do místico (ou do QUÊ) não pode ser dito em linguagem abstrata. Todavia, por outro lado, ele mesmo estabelece como objeto de investigação da filosofia justamente o QUÊ. "A minha filosofia", afirma Schopenhauer, "de modo algum investiga DE ONDE veio o mundo nem PARA QUE existe; mas apenas o QUÊ [Was] ele é" (W I, $\mathbf{1 5}$, p.97). Então, colocamos um problema: de que modo a filosofia nos comunica o QUÊ, se aquilo que ela investiga ultrapassa a experiência e, portanto, não pode ser dito? No fundo, a doutrina schopenhaueriana aponta para o fato de que a linguagem só é capaz de dizer COMO o mundo é, e não o QUÊ ele é. Esse limite da linguagem é tratado por Schopenhauer especialmente no Suplemento 48, quando o autor delimita aquilo que sua filosofia pode dizer daquilo que ela não pode dizer:

[...] o seu tema [da filosofia] tem de limitar-se ao mundo: dizer sob todos os aspectos o QUÊ o mundo É, o que o mundo É no seu mais íntimo, é tudo, o que a filosofia honestamente pode realizar. - Isso, então, corresponde ao fato de que a minha doutrina, quando chega ao seu ponto culminante, assume um caráter NEGATIVO, portanto, é concluída com uma negação. A saber, ela não pode falar aqui senão daquilo que é negado, suprimido: quanto às vantagens obtidas e conservadas, ela é obrigada a descrever (na conclusão do quarto livro) como nada, e pode apenas acrescentar o consolo, de que é tão somente um nada relativo, não absoluto. (W II, cap.48, p.729; grifo nosso).

Portanto, o máximo que a filosofia pode falar sobre o QUÊ é de modo negativo, ou seja, descrevendo aquilo que está sendo negado, suprimido, e jamais o QUÊ o mundo realmente é. Nesse sentido, Barboza escreve:

[...] algo dramático para alguém, o filósofo, que lida primariamente com a linguagem no ofício de expressar-se sobre a condição humana e do cosmo. O sentido do mundo não é apreensível pela linguagem (como já não era o acesso à coisa em si, feito pelo sentimento interno da causalidade corporal). Paradoxalmente, é no silêncio que melhor se apreende (sente) o sentido daquilo que pode ser claramente dito. É no silêncio que se apreende o quê do como do mundo. (BARBOZA, In: W I, p. XXI).

Ainda que a filosofia, no seu auge, fale do QUÊ de forma negativa, a melhor forma de apreendê-lo genuinamente, como bem nota Barboza, é através do silêncio (Schweigen). Isso explica por que Schopenhauer afirma que sua descrição da negação da vontade de vida é fria, pois meramente abstrata (W I, \$68, p.445): o conhecimento do qual procede a negação da vontade nunca encontrará sua expressão perfeita em conceitos abstratos, já que se trata de um conhecimento intuitivo, e não de um conhecimento ordinário. Por mais que Schopenhauer se 
esforce para descrever a negação da vontade, jamais irá esgotá-la abstratamente. Sendo assim, era de se esperar que, quando Schopenhauer chegasse no ponto mais alto de sua filosofia (momento em que ele a conclui com uma negação), a partir de então, o autor se silenciasse. No entanto, de acordo com a nossa interpretação, não é isso o que acontece. Nas seções finais do livro IV d' O Mundo, depois de falar daquilo que é negado, suprimido, Schopenhauer começa a mencionar uma série de alegorias cristãs no seu discurso filosófico ( Cf. W I, \$70). Por que o nosso autor faz isso, ao invés de se voltar ao silêncio? Do nosso ponto de vista, o objetivo principal de Schopenhauer era abordar o QUÊ de forma alegórica, tal qual fazem algumas religiões, por isso, ele "empresta" suas alegorias. O cristianismo, afirma Schopenhauer, "ensinou, em verdade, a grande verdade da afirmação e da negação da Vontade de vida, envolta na roupagem da alegoria" (W II, cap.48, p.747).

Para compreendermos melhor esse ponto, devemos lembrar que tanto a filosofia quanto a religião são metafísicas (W II, cap.17, p.200), para o nosso autor, e isso não significa, de modo algum, que Schopenhauer despreze o papel da segunda metafísica, pois, como ele mesmo escreve: "as religiões fazem perfeitamente as vezes de uma metafísica objetivamente verdadeira” (Id., p.203). No fundo, ambas as metafísicas tratam da mesma coisa, embora falem linguagens diferentes: a verdade da filosofia é dita sensu stricto et proprio, enquanto a verdade da religião, sensu allegorico. De outro modo, a filosofia fala do QUÊ de modo negativo; a religião, de modo alegórico. $\mathrm{Na}$ verdade, para sermos mais fieis aos termos schopenhauerianos, no tocante à linguagem das duas metafísicas, devemos empregar, respectivamente, os verbos dizer e mostrar, como podemos observar na citação a seguir:

[...] a filosofia está para a religião como uma linha reta única está para várias linhas curvas que correm ao seu lado: pois a filosofia diz [spricht] sensu proprio, portanto, alcança diretamente o que a religião mostra [zeigt] sob velamentos e alcança só por desvios. (W II, cap.48, p.749; grifo nosso) $)^{3}$.

Seguindo a nossa linha de interpretação, podemos afirmar então que Schopenhauer tem plena consciência de que ele não pode dizer ao leitor o QUÊ é o mundo (a verdade não pode ser dita pura e abstratamente), porém, ele também sabe que, se agir à semelhança de algumas doutrinas religiosas, poderá mostrar o QUÊ alegoricamente - e é exatamente isto o que o nosso autor faz: prefere o QUÊ alegórico ao silêncio. No tocante à esfera linguística, Schopenhauer prefere, portanto, migrar para o campo místico, a nada dizer; e isso explica sua mudança de linguagem (da filosófica para a alegórica) sobretudo na seção 70.

Para melhor entendermos em que sentido Schopenhauer usa o verbo mostrar, quando se trata do QUÊ alegórico, recorreremos, primeiramente, a uma

\footnotetext{
${ }^{3} \mathrm{Na}$ citação, trocamos "exprime" por "diz", com o intuito de realçar a diferença entre o dizer e o mostrar, que Wittgenstein irá, depois, explorar. A seguir, ficará mais claro por que, no caso da segunda metafísica, devemos usar mostrar; e não dizer:
} 
passagem dos Manuscritos póstumos, na qual Schopenhauer compara o papel do filósofo ao do artista:

[...] ele [o filósofo] é um artista racional [Vernunftkünstler] e seu negócio, em outras palavras, sua arte é copiar para sua faculdade de razão o mundo inteiro, isto é, todas as representações e também o que é encontrado dentro da nossa natureza interior (não como representação, mas como consciência) para combinar conceitos de acordo com tudo isso, e consequentemente, de modo fiel, repetir em abstrato o mundo e a consciência [...]. Essa filosofia será, portanto, perfeitamente pura, como todo trabalho genuíno de arte [...]. Mas o objeto da filosofia, da arte cujos meros materiais são os conceitos, é somente a Ideia (platônica): portanto, o filósofo apreende as Ideias de tudo aquilo que está na consciência, o que aparece como objeto; como Adão, ele está diante da nova criação e dá a cada coisa o seu nome: então, ele depositará as eternas Ideias vivas nos conceitos mortos e deixará solidificar, como o escultor faz a forma em mármore. (HN I, p.117; grifo nosso). ${ }^{4}$

Sabe-se que, na estética schopenhaueriana, o sujeito contempla fixamente um objeto, em detrimento dos demais ao seu redor, a ponto de fazer com que aquela distinção entre sujeito e objeto desapareça: sujeito e objeto tornam-se então uma só coisa. Ou, como diz Schmidt (2005, p.21), sujeito e objeto chegam à unio mystica na efêmera experiência. "A gente se PERDE por completo nesse objeto", afirma Schopenhauer,

[...] isto é, esquece o próprio indivíduo, a própria vontade, e permanece apenas como claro espelho do objeto: então é como se apenas o objeto ali existisse, sem alguém que o percebesse, e não se pode mais separar quem intui da intuição, pois ambos se tornaram uma coisa só, na medida em que toda a consciência é integralmente preenchida e tomada por uma única imagem intuitiva. (W I, \$34, p.206).

Na pura contemplação não ocorre intuição empírica do conhecimento, mas somente intuição das Ideias, pois agora o objeto de conhecimento não é mais algo sensível, e sim as Ideias, as quais correspondem à objetidade mais adequada da vontade $^{5}$ - eis por que somente por meio delas poderemos obter um conhecimento propriamente dito da essência do mundo. A intuição do gênio ou artista é, portanto, de uma outra modalidade de conhecimento, e seu objetivo último é transformar as Ideias apreendidas por pura contemplação em obra de arte. Todavia, notamos que, embora o artista tenha um papel diferente do filósofo, cuja tarefa é realizada por meio de conceitos, Schopenhauer os equipara: fato que

\footnotetext{
${ }^{4}$ Barboza já notou o parentesco entre poesia e filosofia, bem como considerou o filósofo como um artista racional em: BARBOZA, J. Metafísica do belo de Arthur Schopenhauer. São Paulo: Humanitas, 2001; p.119.

5 As Ideias (entendidas por Schopenhauer no sentido platônico) são modelos fixos, imutáveis e encontram-se fora do espaço e do tempo, por isso, são alheias à pluralidade e independentes do princípio de razão. Nas palavras de Schopenhauer, a definição de Ideia é dita do seguinte modo: "entendo, pois, sob IDEIA, cada fixo e determinado GRAU DE OBJETIVAÇÃO DA VONTADE, na medida em que esta é coisa em si e, portanto, é alheia à pluralidade. Graus que se relacionam com as coisas particulares como suas formas eternas ou protótipos" (W I, 『25, p.151).
} 
coincide com a nossa interpretação neste artigo, pois a filosofia só pode ser realmente capaz de investigar o QUÊ, como defende Schopenhauer, se o filósofo agir também feito um artista, caso contrário, o QUÊ torna-se, para ele, algo inacessível. ${ }^{6}$

Por que afirmamos que, para Schopenhauer, uma obra de arte mostra o QUÊ do COMO do mundo? Porque, em algumas passagens, Schopenhauer sugere que, diante de sua obra de arte, é como se o artista estivesse apontando para ela e dizendo: vejam, isso é o QUÊ! Nos Manuscritos, por exemplo, o nosso autor escreve: "todas aquelas artes [pintura, estátua, poema, cena de palco e música] mantêm diante do questionador uma figura e dizem: "vejam, isso é o que é a vida!"”. (HN III, p.390-391). Semelhante pensamento encontra-se no Suplemento 34, com as seguintes palavras:

[...] cada obra de arte responde àquela questão ["que é a vida?"], cada pintura, cada estátua, cada poema, cada cena teatral: também a música a responde; e em verdade, mais profundamente do que qualquer outra arte, na medida em que exprime, numa linguagem compreensível imediatamente - todavia não traduzível na da razão -, a essência mais íntima de toda vida e existência. As demais artes, portanto, exibem em conjunto ao perquiridor uma imagem intuitiva e dizem: "Vê aqui, eis a vida!". (W II, cap.34, p.487).

Numa outra passagem, Schopenhauer é mais explícito e afirma: "o intento, todavia, com o qual o poeta põe em movimento a nossa fantasia é o de manifestarnos as Ideias, isto é, mostrar [zeigen] em um exemplo o que é a vida, o que é o mundo" (W II, cap.37, p.510; grifo nosso). Vale lembrar que, em se tratando das artes discursivas, Schopenhauer não condena a presença de alegorias, mas, pelo contrário, considera-as importantíssimas, pois são elas que irão conduzir o leitor à apreensão das Ideias (à apreensão do QUÊ). É nesse sentido, portanto, que dissemos outrora que algumas religiões conseguem mostrar o QUÊ de forma alegórica, afinal, suas alegorias, no fundo, são poéticas - considerem-se aqui também as poesias do Sufi, ora chamadas por Schopenhauer de "mística do sufismo" (W II, cap.48, p.730). ${ }^{7}$

A seguir, veremos de que modo o drama do filósofo, que não pode dizer o que só pode ser mostrado, irá aparecer de forma semelhante no Tractatus. A nossa leitura do Tractatus tem como base fundamental a obra Iniciação ao silêncio. Análise do Tractatus de Wittgenstein (ver bibliografia) de Margutti Pinto.

\footnotetext{
${ }^{6}$ Ver também outra referência na qual Schopenhauer aproxima a filosofia da arte: W I, p.317. Noutro trecho, Schopenhauer reforça seu posicionamento acerca da íntima proximidade entre a filosofia e a arte, afirmando que sua filosofia não é ciência, mas sim arte (HN I, p.126), e então aponta o erro dos sistemas anteriores: "há tanto tempo, tentativas vãs e infrutíferas foram feitas na filosofia, porque a procuraram no caminho da ciência, em vez da arte" (HN I, p.154). Novamente, no terceiro Manuscrito, o autor, depois de afirmar que o objetivo de toda arte é resolver o problema da existência (Daseyn), relaciona a filosofia com as belas artes (HN III, p.390-391).

${ }^{7}$ Essa interpretação foi tema da minha tese de doutorado, ver: PICOLI, 2018. E não é minha intenção, neste artigo, desenvolver especialmente esse ponto da filosofia schopenhaueriana, mas sim dar destaque à assimilação do pensamento schopenhaueriano por Wittgenstein.
} 


\section{CiÊNCIA, FILOSOFIA E Místico No TRACTATUS}

Em seus Diários (1914-1916), coletânea de textos que reúne anotações prévias à publicação do Tractatus (1921), Wittgenstein escreve sobre a origem do nosso impulso (Trieb) para o místico nas seguintes palavras:

[...] o impulso para o místico origina-se da insatisfação de nossos desejos através da ciência. Nós sentimos que, mesmo quando todas as questões científicas possíveis são respondidas, nosso problema ainda não foi, de modo algum, tocado. Sem dúvida, então não permanece mais nenhuma questão; e justamente essa é a resposta [Cf. 6.52]. (TG, p.143; 25/ 05/ 15).

A passagem acima nos remete à distinção schopenhaueriana entre ciência e filosofia. Relembremos que, para Schopenhauer, o objeto de estudo das ciências são as aparências, bem como suas relações entre si, e seu objetivo é responder ao COMO ou POR QUÊ? do mundo (W I, \$15, p.95-97). Já o objeto de estudo da filosofia volta-se para o que está além da experiência, ou seja, a essência das aparências, o que, de outra forma, equivale a dizer que sua pergunta é pelo QUÊ do mundo. À luz de Philonenko, Margutti vê traços spinozanos nesse pensamento schopenhaueriano e bem observa a relação da filosofia de Schopenhauer com a arte:

[...] o homem vulgar calcula; o gênio, em sua profundidade ética, não (Philonenko 1980: 131). Isso conduz a uma dicotomia entre a ciência e a filosofia, que, na opinião de Philonenko, constitui uma contribuição original de Schopenhauer (1980: 127). A ciência, recorrendo à matemática, se preocupa com o fenômeno, sua pergunta é pelo onde, como, quando e por quê; a filosofia suspende o princípio de razão e se preocupa com a essência, sua pergunta é pelo quid(ibidem: 119; 122). Neste ponto, a apropriação que Schopenhauer faz de Spinoza é bastante inovadora [...]. Nesse sentido, ciência e filosofia constituem duas dimensões completamente distintas. A ciência está interessada no mundo e nos proporciona um conhecimento-utensílio; a filosofia pretende contemplar a essência do mundo e nos proporciona um conhecimento ontológico (ibidem: 123). A ciência é a realização do homem comum, que é interessado e, nessa perspectiva, ordinário e vulgar; a filosofia é realização do gênio, que visa contemplar desinteressadamente o universal. (MARGUTTI PINTO, 1998, p. 5758.).

Wittgenstein herda, em parte, a distinção schopenhaueriana entre ciência e filosofia, pois encarrega a filosofia da atividade de delimitar o que realmente pode ser pensado acerca dos fatos do mundo; porém, Wittgenstein não coloca como tarefa da filosofia estudar aquilo que se encontra fora dos fatos do mundo, âmbito também denominado por ele de "místico". Como nota Zilles, à semelhança de Kant, Wittgenstein rejeita a metafísica como sistema filosófico, estabelecendo limites lógicos ao conhecimento: "Kant tentou demarcar os limites do pensamento; Wittgenstein, os limites da linguagem. Kant delimitou o conhecimento factual; Wittgenstein, o discurso factual" (ZILLES, 1991, p. 89-90). À filosofia fica delegada 
simplesmente a tarefa do esclarecimento lógico dos pensamentos ou das proposições da ciência, pois quem se preocupa com a veracidade das proposições é a ciência; a filosofia interessa-se tão somente pelo sentido das proposições científicas. Wittgenstein ressalta que "a filosofia não é uma teoria, mas uma atividade" (TLP: 4.112, p. 167), e é dessa forma que a filosofia delimita não só o pensável, mas também o impensável (o que está fora do mundo e encontra-se, portanto, no campo místico) (Id: 4.114). Nesse sentido, a visão wittgensteiniana da filosofia como atividade racional, bem como da metafísica como algo inacessível à razão é bem próxima da visão kantiana. Schopenhauer, em contrapartida, considera a filosofia uma metafísica, mas, por outro lado, descarta a possibilidade da razão fornecer qualquer resposta acerca da essência íntima do mundo. É por isso que, para Schopenhauer, tal resposta tem de vir unicamente das Ideias, nunca do princípio de razão. De qualquer forma, aquela dualidade schopenhaueriana acerca do COMO e do QUÊ do mundo é mantida na estrutura argumentativa tractatiana, como podemos conferir nos seguintes aforismos:

6.432: como seja o mundo, é completamente indiferente para o Altíssimo. Deus não se revela no mundo.

6.4321: os fatos fazem todos parte apenas do problema, não da solução.

6.44: o místico não é como o mundo é, mas que ele é. (TLP, p.259).

Wittgenstein segue, portanto, o que ensina Schopenhauer: a questão do enigma do mundo está relacionada a QUÊ o mundo é, e não a COMO ele é; e o QUÊ ele é pertence ao campo místico, não ao mundo. Mas a tese de mundo tractatiana, segundo Margutti, choca a tradição filosófica, pois o mundo, desde Tales, sempre foi entendido como o conjunto de todas as coisas, Wittgenstein, porém, revolve a tradição ao afirmar que o mundo é um conjunto de fatos: "isso significa que a análise do mundo se resolve em fatos, não em coisas" (Margutti Pinto, 1998, p.276-277). Dessa forma, os fatos tornam-se mais relevantes do que as coisas mesmas, e essa posição wittgensteiniana aparece logo na abertura do Tractatus, quando o autor afirma que o mundo é uma totalidade dos fatos, não das coisas (TLP: 1.1, p.129). Ao declarar que o místico diz respeito ao que o mundo é, Wittgenstein coloca o sentido do mundo fora dele, ou seja, não nos fatos. Segundo o autor, os fatos são meramente acidentais, assim como a vida, que, por ser um fato do mundo, é também acidental; porém, um valor não deve jamais corresponder àquilo que é acidental. Por isso, na visão wittgensteiniana, ou algo tem algum valor, ou é um fato do mundo, nunca, portanto, as duas coisas ao mesmo tempo - como nos comprovam as seguintes sentenças:

6.41: o sentido do mundo deve estar fora dele. No mundo, tudo é como é e tudo acontece como acontece; não há nele nenhum valor - e se houvesse, não teria nenhum valor.

Se há um valor que tenha valor, deve estar fora de todo acontecer e ser assim. Pois todo acontecer e ser assim é casual. 
O que o faz não casual não pode estar no mundo; do contrário, seria algo, por sua vez, casual.

Deve estar fora do mundo. (TLP, p.257).

Nesse caso, a ética deve estar onde estão os valores e o sentido da vida, ou seja, fora do mundo, o que explica a asserção de Wittgenstein de que a ética é transcendental (Id: 6.421, p.257). Na verdade, a ética se encontra na mesma dimensão do sujeito transcendental, pois o sujeito, para Wittgenstein, "não pertence ao mundo, mas é um limite do mundo" (Id: 5.632, p.229). O autor então se pergunta como é possível um sujeito metafísico estar no mundo? Para responder a essa questão, Wittgenstein faz uma analogia com o olho, cujo desenho reproduzimos abaixo:

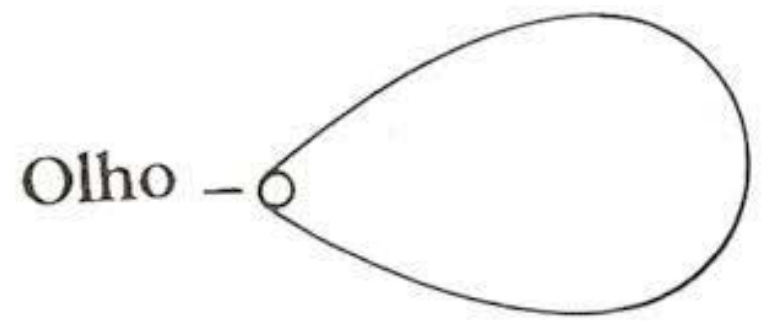

(TLP, 5.6331, p. 247)

Em síntese, a analogia wittgensteiniana do olho significa o seguinte: o olho vê, mas você não vê o olho; e assim como o olho vê o mundo, e não há nada no campo visual que permita concluir que o mundo é visto a partir do olho; da mesma forma, o sujeito transcendental vê o mundo, sem que exista nada no mundo que permita concluir que o mundo é percebido a partir do sujeito. Margutti esclarece essa analogia do seguinte modo:

[...] assim como o olho é limite do campo visual, o sujeito transcendental é limite do mundo. A força da analogia está no fato de que, da mesma forma que o olho não pertence ao campo visual e não pode ser inferido a partir dele, o sujeito transcendental não pertence ao mundo e não pode ser inferido a partir dele. Se ele não pertence ao mundo, ele não existe como fato. (MARGUTTI PINTO, 1998, p. 325).

Tal analogia lembra-nos do "olho cósmico" (Weltauge) de Schopenhauer, mais precisamente, lembra-nos do puro sujeito do conhecimento, o qual não pertence ao mundo, embora esteja nele. Margutti, por sua vez, cria sua própria analogia, para melhor esclarecer a experiência mística do sujeito transcendental, e sugere que a realidade seja considerada como análoga ao entrecruzamento de duas retas ortogonais:

[...] o domínio de uma delas, a horizontal, corresponderia ao mundo; o domínio da outra, a vertical, à vontade schopenhauerianamente entendida como sujeito transcendental. $\mathrm{Na}$ reta horizontal, teríamos os fatos do mundo distribuídos no tempo; 
na vertical, teríamos o sujeito transcendental contemplando atemporalmente a essência do mundo. Enquanto pertencentes do domínio da vertical, temos a capacidade de nos elevar acima das particularidades, pondo em ação nossa dimensão universal, o sujeito transcendental que nos torna capazes de intuir a essência do mundo em sua universalidade (a lógica como lei estruturante da reta horizontal); e o exercício dessa capacidade é um dever ético [...]. O que há de melhor em nós pertence à reta vertical. Temos o dever de ultrapassar a barreira da horizontal para enxergar a infinitude da vertical. Originariamente sujeito transcendental, a vontade tem a obrigação ética de levantar o véu representado pela prisão espaço-temporal do mundo dos fatos para intuir, no âmago desse mesmo mundo, a essência imutável e eterna de toda a realidade. Nesse sentido, parece que aquilo que 'se mostra' equivale ao objeto da intuição intelectual (em sentido schopenhaueriano) do sujeito transcendental. (Id., p. 243-4).

A intuição mística ocorre justamente no ponto de intersecção das duas retas, onde a lógica se funde com a ética, e também com a estética, pois, após afirmar que a ética é transcendental, Wittgenstein imediatamente acrescenta: "ética e estética são uma só” (TLP: 6.421, p.257). O autor não nos dá demais esclarecimentos sobre tal proposição, mas, de qualquer forma, ela nos remonta a Platão (1973, VI, 484c), para quem o justo, o bom e o belo são apreendidos, de um só golpe, pela Ideia do bom [agathós]. Barboza (2005, p.266) também vê um parentesco entre a estética e a ética de Schopenhauer, através do conceito de negação da vontade, apontando para o fato de que, com a contemplação estética schopenhaueriana, temos uma dissolução, ainda que momentânea, da individualidade, então o mau (o egoísmo essencial em todo ser humano) desaparece. Por isso, não concordamos com a posição de Santos (In: TLP, 2017, p.111) de que Wittgenstein adota a definição schopenhaueriana de experiência estética e a estende por considerar a ética e a estética uma coisa só, afinal, esse raciocínio já pode ser concluído na filosofia de Schopenhauer.

Apesar de herdar traços da filosofia platônica e schopenhaueriana acerca do bom e do belo, Wittgenstein não compactua da ideia de que um método racional ou um arrebatamento místico do sujeito possa trazer quaisquer informações sobre o místico, como defendem, respectivamente, Platão e Schopenhauer, por meio de suas teorias das Ideias. Na visão de Wittgenstein, embora o sujeito seja transcendental (e, dessa forma, podemos dizer que ele participa do místico), o mesmo é incapaz de dizer algo sobre o místico, simplesmente porque se trata de um campo incomunicável, inatingível pela linguagem. É como o indivíduo schopenhaueriano, o qual sabe in concreto o QUÊ é o mundo, pois sua essência é a mesma do mundo, mas não é capaz de descrevêlo in abstracto. 


\section{O MÍSTICO E A TRANSCENDÊNCIA DA LINGUAGEM}

De acordo com a filosofia do Tractatus, tudo o que compõe o campo lógico da linguagem pode ser pensado e, por conseguinte, pode ser dito. Mas há também o que não pode ser pensado, nem dito, embora possa ser mostrado: esse é justamente o caso do místico, campo que transcende a linguagem. Segundo Margutti:

[...] no Tractatus, Wittgenstein pretende resolver, do ponto de vista da crítica da linguagem, a antinomia schopenhaueriana entre $\mathrm{O}$ gênio e o homem vulgar, que não apenas é subsidiária da antinomia kantiana entre liberdade e determinismo, mas também envolve as antinomias entre intuição e discurso, arte e ciência, essência e fenômeno, vontade e representação, sujeito transcendental e indivíduo, vida feliz e vida infeliz. A solução tractatiana consiste em dissociar, no interior da linguagem, como expressão do pensar, duas dimensões complementares: aquilo que pode ser dito - o 'dizer' - e aquilo que não pode ser dito, mas de algum modo se revela - o 'mostrar'. (MARGUTTI PINTO, 1998, p.329).

A pretensão de Wittgenstein no Tractatus, como o próprio autor deixa claro no prefácio, é traçar um limite para o pensar; e, para tanto, é necessário separar aquilo que pode ser pensado daquilo que não pode ser pensado. Segundo Wittgenstein, tal limite só pode ser traçado por meio da linguagem, assim, tudo aquilo que estiver fora do alcance da mesma pode ser considerado um contrassenso (TLP, p.125). O desafio do autor será então demonstrar de que forma uma proposição é capaz de representar um estado de coisas, visto que, para ele, o mundo é um conjunto de fatos, ou seja, de coisas interligadas entre si como numa cadeia. Por uma proposição, Wittgenstein entende ser uma figuração (Bild) da realidade: "a proposição é um modelo da realidade tal como pensamos que seja" (Id: 4.01, p. 157). E o conjunto de estado de coisas constitui justamente o que o autor denomina de realidade (Wirklichkeit). Portanto, a essência de cada proposição é a figuração de um fato do mundo, entretanto, tal proposição pode ser real ou simplesmente hipotética. Noutras palavras, a realidade pode corresponder ou não a essa figuração, e isso irá definir se tal proposição em questão é verdadeira ou falsa. "O que a figuração deve ter em comum com a realidade para poder afigurá-la à sua maneira - correta ou falsamente - é sua forma de afiguração" (Id: 2.17, p.137), escreve Wittgenstein, que, a seguir, complementa: "para reconhecer se a figuração é verdadeira ou falsa, devemos compará-la com a realidade" (Id: 2.223, p.139). Na perspectiva wittgensteiniana, a ordem lógica do pensar é a mesma do mundo, e isso explica como é possível que a linguagem corresponda a uma representação figurativa do mundo. Portanto, a condição de possibilidade de qualquer afiguração é justamente essa forma lógica (Id: 2.18, p.139). Para Zilhão:

[...] a lógica possui assim em L.-P.A. a extraordinária importância de ser a armação formal da linguagem, do pensamento e do mundo. Ela é o elemento comum que permite ao pensamento representar a realidade e à linguagem traduzir o pensamento e, por via deste, 
fazer asserções acerca do mundo. Ela é totalmente a priori. De tal modo que se um deus criasse um mundo teria que o criar de acordo com ela. O filósofo, por sua vez, assume-se como o seu guardião, aquele que, ao nível do consciente, consegue mostrar essa estrutura implicitamente presente tanto na organização do mundo físico como na organização do mundo mental. (ZILHÃO, 1993, p.21).

Essa lógica, porém, não pode ser expressa através de proposições, pois as proposições supõem essa mesma forma lógica para poderem representar o mundo, então, seria preciso que existissem proposições fora da forma lógica para serem capazes de representá-la. "Para podermos representar a forma lógica, deveríamos poder-nos instalar, com a proposição, fora da lógica, quer dizer, fora do mundo" (TLP: 4.12, p.167), afirma Wittgenstein. O problema que imediatamente surge é o seguinte: da afirmação de que uma proposição se situaria fora do mundo seguirse-ia a conclusão de que a mesma encontrar-se-ia fora do alcance de nossa linguagem, pois "a linguagem só pode fazer aquilo que a proposição faz: descrever fatos” (MARGUTTI PINTO, 1998, p. 277). Portanto, essa forma lógica, a essência de toda a nossa linguagem, não pode ser jamais descrita, mas tão-somente mostrada: "a proposição mostra [zeigt] a forma lógica da realidade. Ela a exibe" (TLP: 4.121, p.169) e "o que pode ser mostrado não pode ser dito" (Id: 4.1212, p.169).

$\mathrm{Na}$ visão de Wittgenstein, especular sobre a totalidade do mundo não constitui o objeto de investigação do filósofo, pois "o sentimento do mundo como totalidade limitada é o sentimento místico" (Id: 6.45, p.259). O sentido do mundo está fora dele, e a filosofia não é capaz de dizer algo sobre sua forma lógica. Como vimos, Wittgenstein estabelece como função da filosofia o esclarecimento lógico dos pensamentos, ou seja, a filosofia deve clarificar as proposições científicas, impedindo assim que se diga algo sobre o que está além da linguagem. Por isso, também dizemos que a filosofia delimita o que é pensável. "O que é pensável é também possível. Não podemos pensar nada de ilógico, porque, do contrário, deveríamos pensar ilogicamente" (Id: 3.02 e 3.03, p.139), afirma Wittgenstein. Tudo o que compõe a forma lógica da linguagem é possível e pensável, visto que nada pode ser descrito fora dela. Numa carta a Russell (19/ 08/ 1919), Wittgenstein reforça esse ponto da filosofia tractatiana:

[...] eu tenho receio de que você não tenha captado minha afirmação essencial, para a qual a coisa toda, com as proposições lógicas, é apenas uma adição. O principal é a teoria sobre o que, através de proposições - isto é, através da linguagem - é dito (e o que equivale ao mesmo, é pensado) e o que através das proposições não pode ser exprimido, e sim apenas mostrado. Esse é, penso eu, o problema principal da filosofia. (WITTGENSTEIN, 1980, p. 88).

Margutti considera que, no tocante ao sentido em que deve ser concebido o papel da filosofia na vida humana, seu resultado é uma verdadeira revolução, pois: 
[...] ela constitui, por um lado, uma crítica da linguagem, cujo exercício deve ser entendido como uma atividade, não como uma doutrina. Por outro, contudo, ao delimitar o que pode ser dito, a crítica mostra que nem a questão nem a resposta sobre o sentido da vida podem ser formuladas linguisticamente. A crítica clarifica a lógica da linguagem de modo a tornar patente a impossibilidade do discurso filosófico, inclusive aquele por meio do qual ela se expressa. Assim, ao ensinar que o enigma não existe, ela ensina simultaneamente a lição de que não se pode sequer dizer que o enigma não existe. (MARGUTTI PINTO, 1998, p. 251-252).

Para Wittgenstein, à semelhança de Schopenhauer, o místico não é sequer pensável, não podemos nem mesmo formular uma questão sobre ele. E, de acordo com a doutrina de Schopenhauer, podemos por assim dizer que o objeto de estudo da filosofia encontra-se no campo místico, visto que sua tarefa é investigar o QUÊ é o mundo. Por conseguinte, em se tratando da linguagem, para que a filosofia obtenha êxito em seu propósito, ela não tem outra alternativa senão adentrar-se no campo místico: o que é feito mediante o arrebatamento místico das Ideias. Wittgenstein, provavelmente, estaria totalmente de acordo com o fato de que o QUÊ schopenhaueriano corresponde ao enigma do mundo e encontra-se num campo inacessível à linguagem; mas não concordaria que a experiência mística seja algo capaz de ser mostrado por linguagem alguma. Semelhante a Schopenhauer, Wittgenstein também defende que a linguagem desaparece no âmbito místico, é por isso que ele resguarda-se ao silêncio, depois de proferir seu último aforismo do Tractatus: "sobre aquilo que não se pode falar, deve-se silenciar" (TLP: 7, p.261). Na visão de Margutti, as proposições da filosofia acabam se revelando verdadeiros contrassensos, e, em razão disso, devem ser abandonadas em prol do silêncio:

[...] as proposições da metafísica [...] pretendem descrever o que existe em sentido absoluto, ou seja, a essência do mundo. Esta última, porém, é a condição de possibilidade dos fatos e de sua descrição e, embora seja pressuposta por qualquer proposição, não pode ser descrita. Nesse sentido, o enigma filosófico não existe porque não pode ser formulado linguisticamente. Assim, o ceticismo não é irrefutável, mas mero contrassenso. E, se todas as questões científicas fossem resolvidas, as questões metafísicas permaneceriam intocadas. Em virtude disso, o método correto em filosofia consiste em mostrar que dada proposição metafísica não tem o conteúdo descritivo que pretende ter e é, portanto, um contrassenso. Nesse ponto, a clarificação conceitual é tal que as próprias proposições do Tractatus se revelam contrassensos, devendo ser abandonadas. Daí o apelo final ao silêncio. (MARGUTTI PINTO, 1998, p. 253).

Tal qual Schopenhauer, Wittgenstein não nega o místico: "há por certo o inefável. Isso se mostra, é o Místico" (Id: 6.522, p.261). Como a linguagem wittgensteiniana só pode descrever os fatos do mundo, o verbo 'dizer' refere-se tão somente a esses fatos, à aparência, nunca ao místico mesmo, à essência do 
mundo. As proposições que a filosofia trabalha, afirma Wittgenstein, só podem dizer como uma coisa é, nunca o que ela é (Id: 3.221, p.143). Que nada pode ser dito acerca do místico não significa que o místico não possa ser experienciado, ele certamente o pode; e, para Wittgenstein, isso se faz por meio do silêncio. Margutti, à luz de Walter Stace, observa que a experiência mística de Wittgenstein não é intrinsecamente um fenômeno religioso e defende que aquilo que se convencionou chamar de "experiência mística" deveria ser mais adequadamente chamado de "consciência mística":

[...] a palavra 'experiência' é entendida como um produto de intelecto conceitual, ao passo que o misticamente "experimentado" é um modo da consciência não-intelectual (ibidem: 314). A consciência ordinária (sensório-intelectual) envolve sensações, imagens e conceitos, ao lado de emoções, desejos e volições (ibidem: 316). A consciência mística é totalmente incomensurável com a anterior, embora não seja necessariamente sobrenatural (ibidem: 317). A característica central das "experiências" místicas descritas nas várias culturas é a apreensão de uma unidade última de caráter não-sensível em todas as coisas, a qual transcende a consciência ordinária (ibidem: 318). Num sentido mais rigoroso, a "experiência" é a unidade. Em virtude disso, os místicos sentem não só que sua "experiência" está fora do tempo, mas também que ela é mais real que qualquer outra experiência (ibidem: 314). (MARGUTTI PINTO, 1998, p.242).

Esse mesmo raciocínio é válido para o pensamento schopenhaueriano e pode, aliás, explicar por que Schopenhauer, inicialmente, denominou de "consciência melhor" (HN I, p.137, p.151, pp.166-167, dentre outras passagens) aquilo que, mais tarde, chamaria de "negação da vontade". Nos primeiros Manuscritos, Schopenhauer contrapõe "consciência empírica" e "consciência melhor", indicando que, enquanto aquela corresponde à consciência ligada ao mundo sensível, a última corresponde ao que se entende por "consciência mística", quando então o sujeito, num êxtase, transcende a consciência empírica e vivencia um momento extratemporal e extraespacial.

\section{O CONFLITO ENTRE O DIZERE O MOSTRARNA FILOSOFIA TRACTATIANA}

A nossa breve análise da estrutura argumentativa do Tractatus nos fez notar quão próximas são as visões de Schopenhauer e Wittgenstein. Se, por um lado, Wittgenstein conclui que as proposições nada podem dizer acerca do místico, restando-nos tão somente o silêncio como forma de apreender o que o mundo é, por outro lado, à idêntica conclusão Schopenhauer já chegara, antes, em seu sistema. O último aforismo de Wittgenstein, na verdade, retoma aquilo que Schopenhauer já concluíra na $\$ 70$ d' O Mundo e voltará a repetir no Suplemento 48: "o que em compensação se ganha e guarda, ela [a minha doutrina] é obrigada a descrever (na conclusão do quarto livro) como nada [...]" (W II, cap. 48, p.729). O que é o místico? Nada pode ser dito acerca dele, concluem Schopenhauer e Wittgenstein. Safranski bem observa esse ponto coincidente entre as filosofias de Schopenhauer e Wittgenstein, apontando para o fato de que ambos os filósofos 
não negam o místico, o que eles não admitem é que se possa dizer o que ele é. Nesse sentido, Safranski escreve:

[...] que há uma experiência que transcende o entendimento, isso Schopenhauer admite, porém, ele adverte contra o fato de querer atribuir-lhe uma legitimidade intelectual. Assim, mais precisamente, perdemos os dois: o entendimento fala um absurdo, e a experiência perde sua evidência. Schopenhauer, como sabemos, chama essa experiência, tão mal compatível com as categorias do entendimento de "consciência melhor", mas fala apenas cautelosamente sobre isso, não abertamente. O cuidado de Schopenhauer vem da mesma atitude com a qual Wittgenstein, tendo em vista o que verdadeiramente importa, afirma no final de seu Tractatus: "do que não se pode falar, sobre isso deve-se silenciar". Arthur Schopenhauer quer saber exatamente onde o silêncio começa e onde a linguagem, talvez uma linguagem transmutada, ainda é possível. (SAFRANSKI, 2001, p. 296-297 - grifo nosso).

O trecho grifado acima nos relembra a expressão usada por Schopenhauer para se referir à linguagem alegórica da religião, cuja verdade é mostrada através de um veículo mítico, o qual "empresta a roupagem da fábula" (W II, cap. 48, p. 748-749). Como defendemos, Schopenhauer teria usado justamente essa linguagem alegórica para mostrar o que não podia dizer, o místico, pois sua linguagem científica já tinha atingido seu limite, e o autor não poderia continuar com ela. Noutros termos, Schopenhauer preferiu mostrar o místico, ainda que numa linguagem transmutada, em vez de ficar em silêncio. Wittgenstein, por sua vez, não tenta dizer o que não pode ser dito, nem mesmo alegoricamente, reservandose unicamente ao silêncio como forma de mostrar o místico.

Para Margutti (1998, p. 342 e p. 356), no entanto, as proposições do Tractatus cometem o pecado de tentar dizer o que não pode ser dito, embora tais proposições sejam necessárias como atividade filosófica de clarificação ao leitor. Lembremos que, de acordo com o prefácio do Tractatus, tudo o que está fora do alcance da linguagem constitui um contrassenso, para Wittgenstein. Sendo assim, as proposições do Tractatus podem ser consideradas também contrassensos, pois têm a pretensão de dizer algo metafísico, quando tentam falar sobre como as coisas são em sua totalidade, por exemplo, "a totalidade das proposições é a linguagem" (TLP: 4.001, p.165), bem como quando abordam o sujeito transcendental. Dessa forma, tais proposições acabam se tornando metafísicas. Todavia, as proposições metafísicas, no fundo, não contêm nenhum conteúdo descritivo, porque os valores absolutos não podem ser jamais descritos pelas proposições, por conseguinte, as proposições tractatianas nada dizem e nada mostram. Para esclarecermos melhor esse ponto, usaremos a analogia da escada (aforismo 6.54) do próprio Wittgenstein. Segundo o autor, as proposições do Tractatus levam irremediavelmente a contrassensos, devendo ser usadas até o momento em que nos deparamos com o místico, e então depois devemos superá-las: "deve, por assim dizer, jogar fora a escada após ter subido por ela” (TLP: 6.54, p. 261). Margutti, por sua vez, crê que a crítica wittgensteiniana da linguagem acaba levando a própria filosofia de Wittgenstein ao suicídio, pois resulta, por fim, num contrassenso das proposições: 
"a elucidação conceitual, que separa o que pode ser dito do contrassenso, transforma-se em contrassenso quando é dita. Nesse sentido, ela é autofágica" (MARGUTTI PINTO, 1998, p. 341 e p. 343).

De qualquer forma, a lógica tractatiana chega no mesmo consenso que o sistema de Schopenhauer: o que o mundo é, é algo indizível - podemos, porém, apreender o seu verdadeiro significado através do silêncio. Vale lembrar que Wittgenstein foi um neo-schopenhaueriano e os seus escritos trazem várias passagens que lembram as teses de Schopenhauer, há vários trechos dos Diários que podem ser considerados extraídos d' $O$ Mundo, ainda que não tenham referências, ou tenham sido reescritos por Wittgenstein -por exemplo, as seguintes citações: "poder-se-ia dizer (schopenhauerianamente): o mundo da representação não é bom nem mau, e sim o sujeito volitivo" (TG, p.174); "O mundo e a vida são um (5.621) [...]. A vida é o mundo" (Id., p.172).

\section{CONSIDERAÇÕES FINAIS}

Tendo em vista tamanha coincidência nos pensamentos de Schopenhauer e Wittgenstein, a nossa investigação nos leva a pensar seriamente se Wittgenstein não teria extraído sua famosa problemática do Tractatus do sistema de seu predecessor. Tal problemática é comumente conhecida como pertencente à filosofia tractatiana, sendo marcada sobretudo pela famosa sentença: sobre aquilo que não se pode falar, deve-se silenciar. Zilles, por exemplo, escreve: "inegavelmente a distinção entre o dizer e o mostrar caracterizam a filosofia de Wittgenstein" (Zilles, 1991, p.88.), mas, como vimos, trata-se, no fundo, de uma doutrina essencialmente schopenhaueriana, em cujos fundamentos Wittgenstein possivelmente se apoiou para construir o seu pensamento. Por outro lado, enquanto a teoria da linguagem e da lógica schopenhaueriana é de tamanha simplicidade, Wittgenstein as desenvolve brilhante e originalmente.

O apelo ao silêncio perante o místico, como o único recurso de se apreender o verdadeiro significado do mundo, é algo que a filosofia de Schopenhauer não nos deixa dúvidas. Expressões comumente conhecidas como wittgensteinianas para se referir ao místico, como é o caso de zeigen [mostrar] e Schweigen [silêncio], já aparecem, antes, no sistema de Schopenhauer. Zeigen é o verbo que Schopenhauer usa para se referir ao modo como os sistemas religiosos e os poetas se expressam linguisticamente sobre o místico; e Schweigen, o modo de se apreender o místico. Entretanto, é Wittgenstein que emprega o termo mais adequado para se referir ao místico (das Mystische), ao passo que Schopenhauer usa Mystik (mística) ${ }^{8}$. Apesar das coincidências, vale ressaltar também a grande diferença entre esses dois pensamentos, pois, de acordo com a nossa interpretação, Schopenhauer tenta mostrar o místico através da linguagem alegórica; e Wittgenstein, por sua vez, nunca teve semelhante pretensão, por isso, para

\footnotetext{
${ }^{8}$ Há, excepcionalmente, uma passagem na qual Schopenhauer usa a expressão das Mystische, ver: HN III, p.345.
} 
exatamente no limite da linguagem científica, remetendo-nos unicamente ao silêncio.

De nossa pesquisa, segue-se, enfim, a conclusão de que a tese tractatiana acerca da linguagem e do místico nos revela um dos mais fiéis leitores de Schopenhauer. Alguém poderia até mesmo dizer que Wittgenstein faz um tributo ao mestre, quando respeita os limites linguísticos impostos por Schopenhauer - e, assim, num primeiro momento, Wittgenstein parece ter sido mais schopenhaueriano do que o próprio Schopenhauer. Mas a nossa interpretação nos mostrou que, de acordo com a doutrina schopenhaueriana, o filósofo é também um artista-racional, sendo assim, podemos afirmar que o nosso autor, de modo algum, infringiu suas próprias regras: o que Schopenhauer buscava no momento em que tratou o místico de forma alegórica era sobretudo nos mostrar o lado artístico de sua filosofia.

\section{REFERÊNCIAS}

BARBOZA, J. Infinitude subjetiva e estética: natureza e arte em Schelling e Schopenhauer. São Paulo: Ed. UNESP, 2005. Metafísica do belo de Arthur Schopenhauer. São Paulo: Humanitas, 2001.

KANT, I. Crítica da razão pura. Tradução de Manuela P. dos Santos \& Alexandre F. Morujão. Lisboa: Fundação Calouste Gulbenkian, 1989.

MARGUTTI PINTO, P. R. Iniciação ao silêncio. Análise do Tractatus de Wittgenstein. São Paulo: Loyola, 1998.

PICOLI, G. T. Os limites da linguagem e o místico na filosofia de Arthur Schopenhauer. Tese (tese de doutorado) - Instituto de Filosofia e Ciências Humanas, Departamento de Filosofia. Universidade Estadual de Campinas, 2018.

PLATÃO. A República. Tradução de J. Guinsburg. São Paulo: DIFEL, 1973.

SAFRANSKI, R. Schopenhauer und die wilden Jahre der Philosophie. Frankfurt am Main: Fisher Verlag, 2001.

SCHMIDT, A. "Wesen, Ort und Funktion der Kunst in der Philosophie Schopenhauers". In: Baum, Günther/ Birnbacher, Dieter (Hg.): Schopenhauer und die Künste. Göttingen, 2005. pp.11-55.

SCHOPENHAUER, A. O mundo como vontade e como representação, tomo I, $2^{a}$. edição. Tradução de Jair Barboza. São Paulo: UNESP, 2015.

O mundo como vontade e como representação, tomo II, 1a. edição. Tradução de Jair Barboza. São Paulo: UNESP, 2015.

Berliner Manuskripte (1818-1830). Frankfurt a.M.: Waldemar Kramer, 19661975. Der handschriftliche Nachlaß in fünf Bände, edição de Arthur Hübscher.

WITTGENSTEIN, L. Tractatus Logico-Philosophicus. Tradução de Luiz Henrique L. dos Santos. São Paulo: Editora da Universidade de São Paulo, 2017. 
WITTGENSTEIN, L. Tagebücher 1914-1916. In: Wittgenstein Werkausgabe. Frankfurt a. M.: Suhrkamp, vol.1, 1984.

Briefwechsel: mit B. Russell, G. E. Moore, J. M. Keynes, F. P. Ramsey, W. Eccles, P. Engelmann und L. von Ficker. Org.: B. F. McGuinness und G. W. von Wright. Frankfurt am Main: Suhrkamp, 1980.

ZILHÃO, A. Linguagem da filosofia e filosofia da linguagem - estudos sobre Wittgenstein. Lisboa: edições Colibri, 1993.

ZILLES, U. Filosofia da religião. São Paulo: Paulus, 1991.

Recebido em: 13-03-2019

Aceito para publicação em: 17-12-19 